\title{
Evaluation on a Promising Natural Cellulose Fiber- Calotropis Gigantea Fiber
}

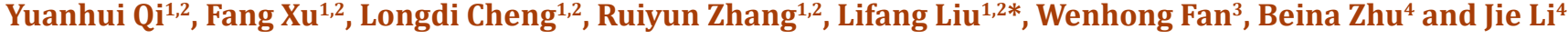 \\ ${ }^{1}$ The Key Lab of Textile Science \& Technology, Donghua University, China \\ ${ }^{2}$ College of Textiles, Donghua University, China \\ ${ }^{3}$ Hu Nan Brocade Group Co.LTD, China
}

${ }^{4}$ China Cotton Textile Association, China

*Corresponding author: Lifang Liu, College of Textiles, Donghua University, China

submission: 㘹March 20, 2018; Published: 眥 May 17, 2018

\begin{abstract}
Calotropis gigantea fiber is a kind of natural cellulose fiber that regains increasing attention nowadays, thus it is evaluated here aiming to replace cotton or kapok fibers to some extent. New discoveries are found about its morphological structure, indicating that it has sharper, closed tip and coarser, open end, and that it usually has 4-6 grooves along its longitudinal axis, with fully distributed microvillus on its surface. The FTIR spectrum shows the fiber mainly contain cellulose, lignin and hemi-cellulose component. X-ray diffraction analysis shows that the fiber has higher crystallinity in comparison with kapok fiber. In term of breaking strength, the fiber is obvious lower than cotton fiber and a little higher than kapok fiber. Furthermore, the fiber has good water absorbing and releasing capability, implying it has excellent water transmissivity.
\end{abstract}

Keywords: Calotropis gigantea fiber; Natural cellulose fiber; Morphological structure; Water transmissivity

\section{Introduction}

Calotropis gigantea commonly known as mudar or milk weed, is a kind of perennial shrubs found chiefly in China, India, Malaysia, as well as most of Asia and large parts of Africa and South America [1-3]. The plant grows easily on varieties of soils and can flower and fruit throughout the year $[3,4]$. It usually grows in slope with low altitude and sunny exposure or in a wide-open area and has good properties of resisting to drought, salinity, and water logging [5]. In addition, it requires no fertilizers or pesticides [6-7]. Generally speaking, the plant is abundant, cheap, and environmental friendly. The applications of different components of the plant have been discussed. The stems and branches have been used as fuel with long history [8]. The medicinal functions of the various parts of this plant have been widely reported $[6,7,9]$. Furthermore, the seeds easily propagated from the plant are reported to be an acceptable feedstock for biodiesel $[3,10,11]$. Besides, there is still a very import part of the plant can be used widely, that is, calotropis gigantea fiber. Fibers can be obtained from the seeds or stems of the plant [12-15]. This paper only focuses on seed fibers.

Calotropis gigantea fiber is not newly coming. The quite earlier report on this fiber was found in 1984 [5], implementing study on the feasibility of using it to make textile fabric by blending with cotton or synthetic fibers. From then on, certain amount of literature can be searched on fiber structure, chemical treatment, biodegradability and natural antibacterial activity [13,14,16,17]. Previous studies show that, calotropis gigantea fiber is a kind of natural cellulose fiber, mainly composed of cellulose, hemicellulose, lignin, pectin, water soluble substance, wax, and ash $[13,16]$. It seems like a tube with thin wall and high hollowness just like kapok fiber, and is commonly used to reinforce composites [13].

Calotropis gigantea fiber regains high attention today benefiting from its renewability and biodegradability when the demand for sustainable and environmental friendly materials as alternatives to petroleum-based materials is extremely urgent [18]. Therefore, relative research on its application in place of some other natural cellulose fibers, such as kapok fiber, bast fiber, even cotton fiber to some extent, is undoubtedly becoming hot. As mentioned above, calotropis gigantea fiber has tubular structure as kapok fiber. It is reported that Kapok fiber can be used as buoyancy materials, oil-absorption materials or microbial fuel cells [19-22], so similar applications can also be speculated regarding calotropis gigantea fiber. Furthermore, former researches indicate that calotropis gigantea fiber can be used for textile fabrics $[5,16]$, so investigation on its properties related to fabric wear ability should be implemented. 
The present study only sheds light on the evaluation of calotropis gigantea fiber, mainly involving its morphological structure, mechanical strength, and water absorbtivity and releasing capability. Although the researches on morphological structure of calotropis gigantea fiber have been reported, new discoveries are found in this study, which is worth reporting. The research on mechanical strength is to guarantee its application life, and that on water absorbtivity and releasing capability are to judge its water transmissivity.

\section{Materials and Methods}

\section{Material}

The calotropis gigantea fibers were obtained from Tharaka, Kenya. Kapok fiber and cotton fiber from Yunnan province and Xinjiang region, China, respectively, were selected as comparison specimens.

\section{Test and analysis}

Microscopies: Scanning electron microscopy (SEM) (JMS$5600 \mathrm{LV}$ ) was used to observe the surface morphology of the calotropis gigantea fibers at a temperature of $20 \pm 2{ }^{\circ} \mathrm{C}$ and a relative humidity of $65 \pm 3 \%$.

Length, linear density and diameter: The length of calotropis gigantea fiber was determined by Baer diagram in term of effective length, meaning the upper half mean length in the fibro gram. The linear density was determined according to standard GB/T 12411.3-1990. The diameter of fiber was observed with BEION F6 fiber fineness tester (Shanghai Bei'ang Scientific Instrument Co., Ltd, China). The diameter thus obtained is the projection width of the outer edge of fiber.

Fourier transform infrared (FTIR) spectroscopy: FTIR spectra of the fibers were obtained with Nexus-670 Fourier infrared (made by Nicolet) using the attenuated total reflection technique. The samples were dried to constant weight and then finely ground and mixed with potassium bromide, $\mathrm{KBr}$ before infrared analysis.

X-Ray diffraction (XRD): The crystallinity and crystal zone orientation index of the fibers were determined by X-ray diffraction (D/MAX - 2550 PC X-ray diffractometer, RIGAKU) at room temperature.

Tensile properties: The tensile properties of calotropis gigantea fibers were obtained by standard GB5886-1986.

Water absorbing capability: The water absorbing capability of fiber was represented with the term of moisture regains that

Table 1: The length and linear density of fibers. determined by standard GB/T 9995-1997 at a temperature of $20 \pm 2^{0}$ $\mathrm{C}$ and relative humidity of $65 \pm 3 \%$. Moisture regain was calculated as following:

$$
W=\frac{G-G_{0}}{G_{0}} \times 100 \%(1)
$$

Where $W$ is the moisture regain of fiber, \%; $G$ is the weight of fiber with water, $g$; $G_{0}$ is the weight of dry fiber, $g$.

Sweat releasing capability: The sweat used in this study was formulated with $1 \mathrm{~L}$ distilled water; $6 \mathrm{~mL}$ ice acetic acid and $5 \mathrm{~g}$ sodium chloride according to standard GB/T14576-2009. Take a certain amount of dried fibers (about $1 \mathrm{~g}$ in this study), weighed and recorded as $m_{0}(g)$; then immersed the fibers into the sweat for $5 \mathrm{~min}$; took out the fibers, weighed when no sweat dripping and recorded as $m_{1}(\mathrm{~g})$; weighed the fibers every $1 \mathrm{~h}$ till constant weight, and recorded the weight as $\mathrm{m}(\mathrm{g})$. The sweat releasing capability is characterized as sweat transmissibility $\mathrm{S}$, that is, the percentage of released sweat to absorbed sweat:

$$
S(\%)=\frac{m_{1}-m}{m_{1}-m_{0}} \times 100 \%
$$

\section{Results and Discussion}

\section{Morphological investigation}

The morphological structure of calotropis gigantea fibers are shown in (Figure 1). As illustrated in Figure $1\left(a_{1}\right)$, the calotropis gigantea fiber is vertical straight, without wool-like crimps or cotton-like convolutions, and its surface is full of sags and crests, which undoubtedly leading to a quite high specific surface area. Furthermore, there are uncertain numbers of grooves parallel to the fiber axis, usually four to six; but sometimes less than four, such as three for the fiber in Figure $1\left(b_{1}\right)$. In contrast, there are straight tiny stripes parallel to the fiber axis as for kapok fiber (Figure $1\left(a_{2}\right)$ ), and no grooves can be observed. Figure $1\left(b_{1}\right) \&\left(b_{2}\right)$ indicate that calotropis gigantea fiber and kapok fiber both have tubular structure with thin wall and large lumen. Therefore it can be seen that a large amount of still air can be kept in the two fibers, contributing to their usage as buoyancy materials or oil-absorption materials. Tips of the two fibers are both thin, sharp and closed as shown in Figure $1\left(c_{1}\right)$ and $\left(c_{2}\right)$; while their ends are quite different. Figure $1\left(d_{1}\right)$ shows that calotropis gigantea fiber has a polygonal open end, while Figure $1\left(d_{2}\right)$ shows kapok fiber has a closed and bent end; however, both of their ends are quite coarser than tips. Figure $1\left(c_{1}\right) \&\left(c_{2}\right)$ also show that the two fibers both smoothly decrease in diameter along longitudinal direction.

\begin{tabular}{|c|c|c|c|}
\hline Items & Calotropis Gigantea Fiber & Kapok Fiber & Cotton Fiber \\
\hline Effective length /mm & 38.56 & 23.17 & 31.56 \\
\hline CV of length/\% & 11.79 & 28.25 & 17.75 \\
\hline Linear density /dtex & 1.02 & 0.74 & 2.12 \\
\hline
\end{tabular}


Length, linear density and diameter: The calotropis gigantea fiber has the highest length of $38.56 \mathrm{~mm}$ comparing with kapok fiber and cotton fiber as shown in (Table 1). The linear density of Calotropis gigantea fiber is higher than kapok fiber, and obviously lower than that of cotton fiber, which may be explained by the fact that calotropis gigantea fiber and kapok fiber have relatively higher hollowness in comparison to cotton fiber. Furthermore, (Table 1) also shows that calotropis gigantea fiber has the lowest coefficient of variation on length, indicating this fiber has good uniformity that is very valuable for natural cellulose fiber used for textiles.
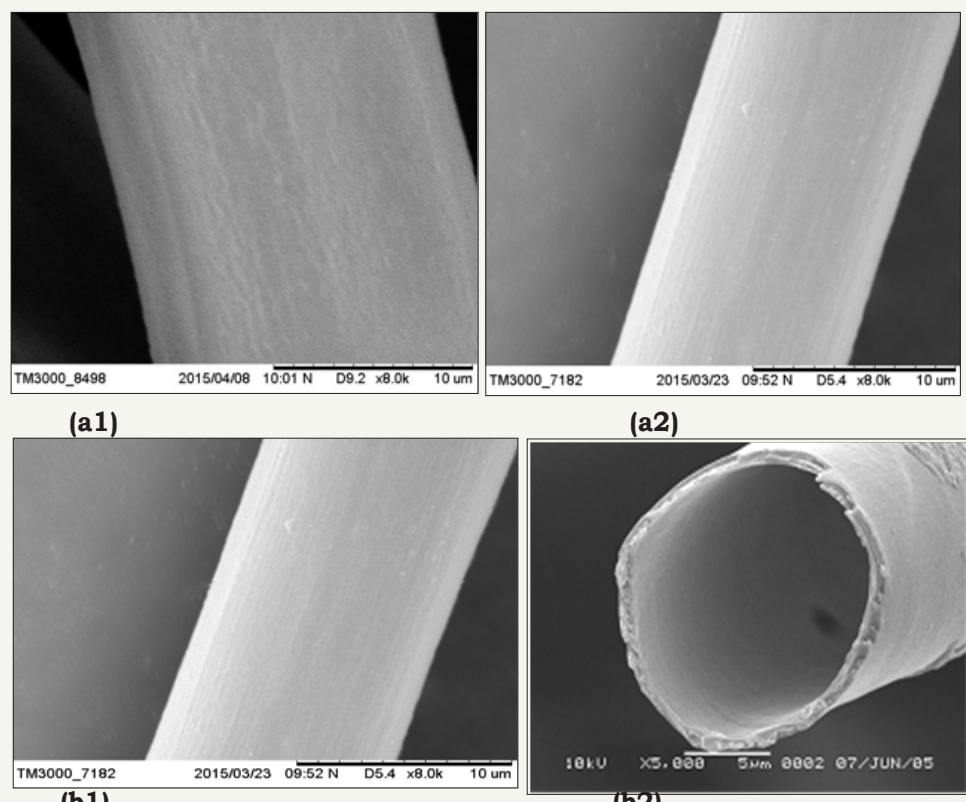

(b1)

(b2)
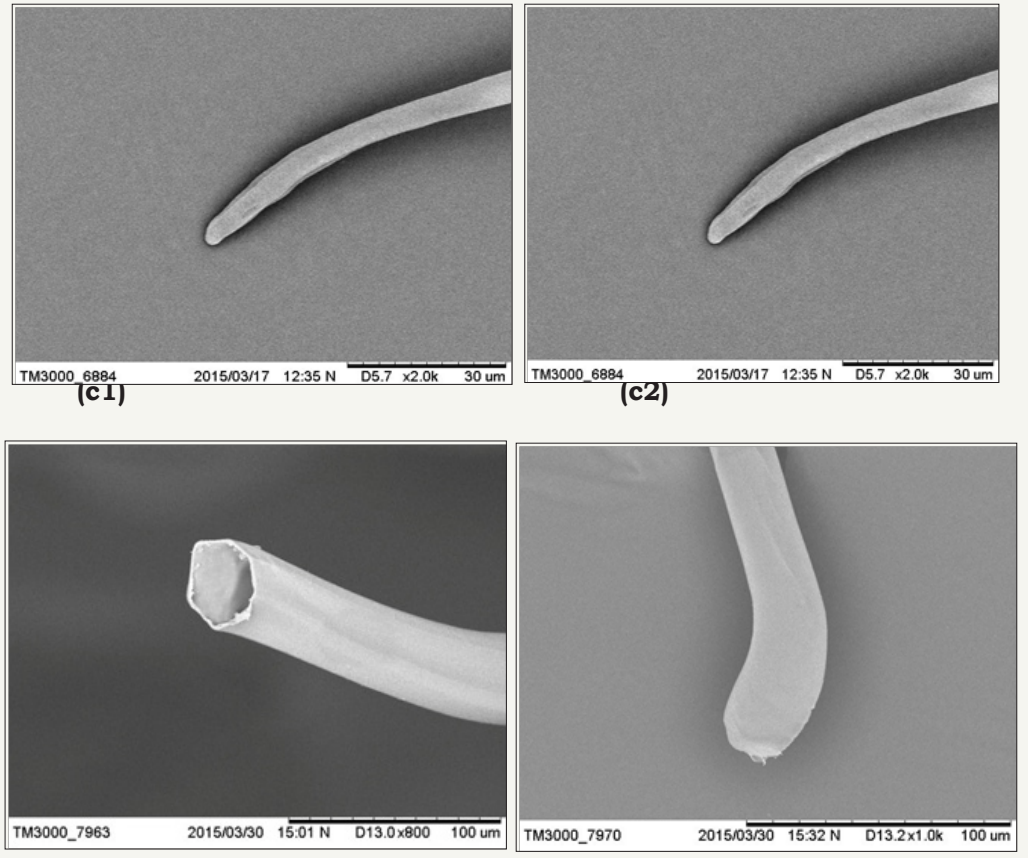

(d1)

(d2)

Figure 1: Morphological structure of fibers: (a1), (a2) longitudinal surface; (b1), (b2) Cross-section; (c1), (c2) Tips; and (d1), (d2) Ends of calotropis gigantea fiber and kapok fiber.

As illustrated in (Figure 1), the calotropis gigantea fiber has sharp tip and coarse end, so we can presume that its diameter should keep reducing from end to tip. Therefore we investigate fiber diameter in detail here. The diameters at certain points along fiber longitudinal elongation are tested and recorded, as shown in (Figure 2). As it can be seen, the diameter at the very end of fiber is thin and sharply increases to the largest value within about $30 \mathrm{um}$ 50um, then keeps decreasing to 0 . 


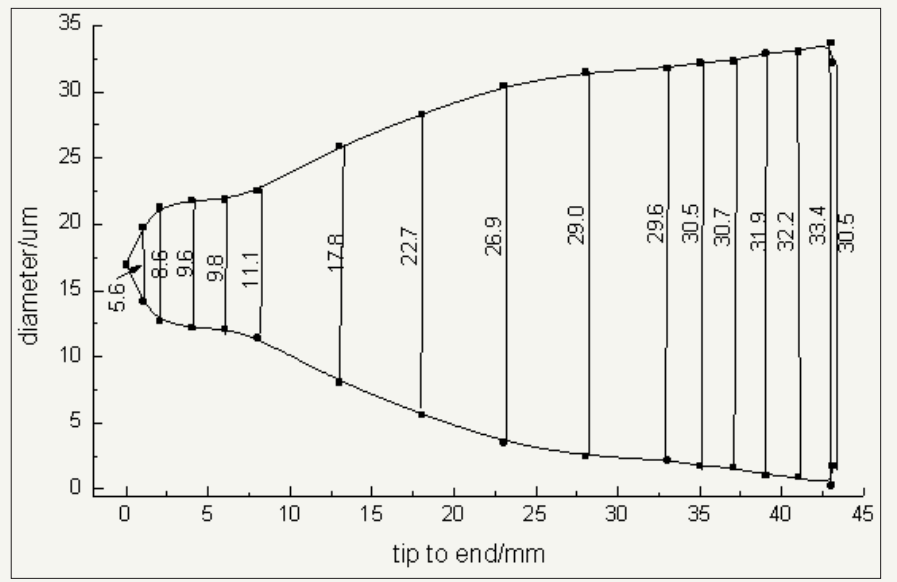

Figure 2: Diameter distribution of Calotropis gigantea fiber.

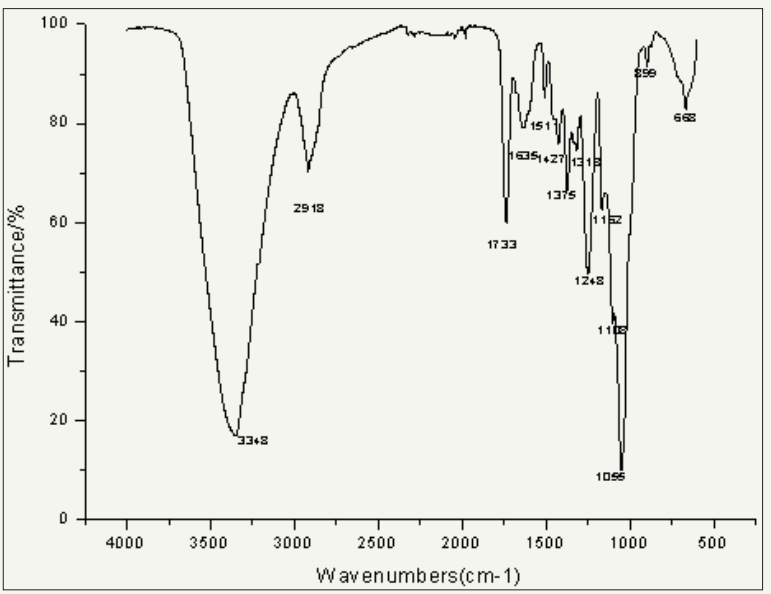

Figure 3: FTIR spectra recorded for Calotropis gigantea fiber.

Spectroscopic analysis (FTIR): (Figure 3) shows the FTIR spectra recorded for calotropis gigantea fiber, and the main peaks are reported in (Table 2). The broad band around $3348 \mathrm{~cm}^{-1}$ is ascribed to the stretching vibration of $\mathrm{O}-\mathrm{H}$, which is the characteristic of all cellulose fibers. The peak at $2918 \mathrm{~cm}^{-1}$ corresponds to the stretching vibration of $\mathrm{C}-\mathrm{H}$. Peaks at $1733 \mathrm{~cm}^{-1}, 1635 \mathrm{~cm}^{-1}$ and $1511 \mathrm{~cm}^{-1}$ respectively correspond to the vibration of $\mathrm{C}=\mathrm{O}, \mathrm{O}-\mathrm{H}$ bond of water absorption, and structure of aromatic ring frame of lignin. The band around $1427 \mathrm{~cm}^{-1}$ corresponds to the bending vibration of $\mathrm{C}-\mathrm{H}$. The band at $1375 \mathrm{~cm}^{-1}$ corresponds to characteristic absorption of methyl, implying hemi-cellulose component occurs in the fiber. Peaks near $1318 \mathrm{~cm}^{-1}, 1248 \mathrm{~cm}^{-1}$ due to the bending vibration of $\mathrm{O}-\mathrm{H}$, the vibration of phenolic hydroxyl, indicate there are lignin component in the fiber. The bands at $1162 \mathrm{~cm}^{-1}, 1108 \mathrm{~cm}^{-1}, 899 \mathrm{~cm}-$ $1,1055 \mathrm{~cm}^{-1}$ are due to the stretching vibration of $\mathrm{C}-0$. The band at $668 \mathrm{~cm}^{-1}$ is assigned to plane deformation vibration of $\mathrm{O}-\mathrm{H}$. The results indicate that calotropis gigantea fibers mainly contain the cellulose, lignin and hemi-cellulose component. The research made by Ashori and Bahreini [13] also shows that fibers from calotropis gigantea seed mainly contain cellulose, hemicellulose and lignin at the content of $49 \%, 20 \%$, and $20 \%$, respectively (the content of hemicellulose is derived from the amount of holocellulose, $69 \%$ ) .
Table 2: Main peak absorption of calotropis gigantea fiber.

\begin{tabular}{|c|c|c|}
\hline No. & Wave Numbers $\left(\mathbf{C m}^{-1} \mathbf{)}\right.$ & Involved Groups \\
\hline 1 & 3348 & Strain O-H \\
\hline 2 & 2918 & Strain C-H \\
\hline 3 & 1733 & C=O stretching \\
\hline 4 & 1635 & $\begin{array}{c}\text { O-H bond of water } \\
\text { absorption }\end{array}$ \\
\hline 5 & 1427 & C-H vibration \\
\hline 6 & 1375 & C-H vibration \\
\hline 7 & 1318 & O-H vibration \\
\hline 8 & 1248 & $\begin{array}{c}\text { vibration of phenolic } \\
\text { hydroxyl }\end{array}$ \\
\hline 9 & $1162,1108,1055,899$ & C-O stretching \\
\hline 10 & 668 & O-H vibration \\
\hline
\end{tabular}

X-ray diffraction (XRD): X-ray diffraction analysis was introduced here to determine the crystallinity and crystallinity orientation index (COI) of calotropis gigantea fiber. The diffraction patterns of calotropis gigantea fiber and kapok fiber are illustrated in Figure 4. The two fibers are both showing typical pattern of 
cellulose I, with well-defined crystalline peaks around $2 \theta=16^{\circ}$ and fiber has stronger and sharper peaks in comparison with kapok $22^{\circ}$ and no doublet at $2 \theta=22^{\circ}$ [18]. However, calotropis gigantea

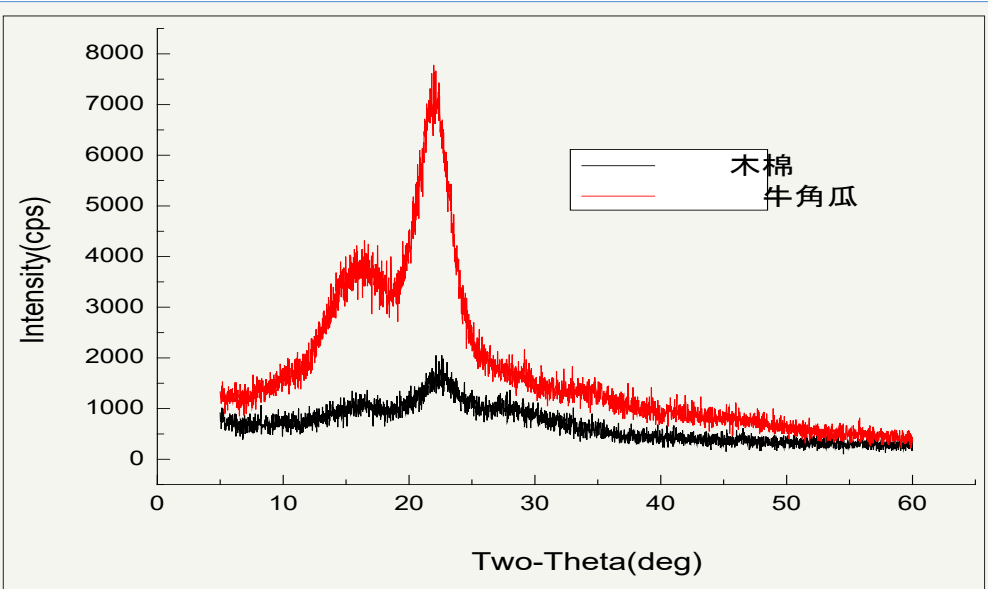

Figure 4: X-ray diffraction patterns of (a) Calotropis gigantea fiber and (b) kapok fiber.

Table 3 shows the crystallinity and the crystallinity orientation index (COI) of calotropis gigantea fiber and kapok fiber. Calotropis gigantea fiber has higher crystallinity and COI value than kapok fiber. Higher crystallinity means higher stiffness and rigidity benefiting from larger crystalline region where molecules have stronger interactions. Higher COI value predicates higher orientation degree in the crystalline area.

Table 3: Crystallinity and crystallinity orientation index of fibers.

\begin{tabular}{|c|c|c|}
\hline Fibers & Crystallinity (\%) & COI (\%) \\
\hline Calotropis gigantea fiber & 43.08 & 80.50 \\
\hline Kapok fiber & 36.18 & 73.29 \\
\hline
\end{tabular}

Tensile strength: The stress-strain curve of calotropis gigantea fiber, as well as kapok fiber and cotton fiber, is drawn as displayed in (Figure 5). The breaking tenacity and elongation of calotropis gigantea fiber are both between those of kapok fiber and cotton fiber. As Zhang et al. [23] reported, cellulose has crystalline structure due to hydrogen bonding interactions and Van der Waals forces between adjacent molecules; on the contrary, hemicellulose and lignin are amorphous in nature [18]. So it can be clearly explained that cotton fiber has obviously higher strength than calotropis gigantea fiber and kapok fiber, owning to its higher cellulose content (95\%$98 \%$ ) and crystallinity (60\%-70\%). Besides, calotropis gigantea fiber and kapok fiber have large lumen making the fibers easier to brittle when stretched, which will undoubtedly reduce their tensile strength. Regarding of calotropis gigantea fiber and kapok fiber, the former has higher crystallinity and COI value as shown in (Table 3), which means well-defined structure and higher orientation degree in crystalline area, leading to higher strength.

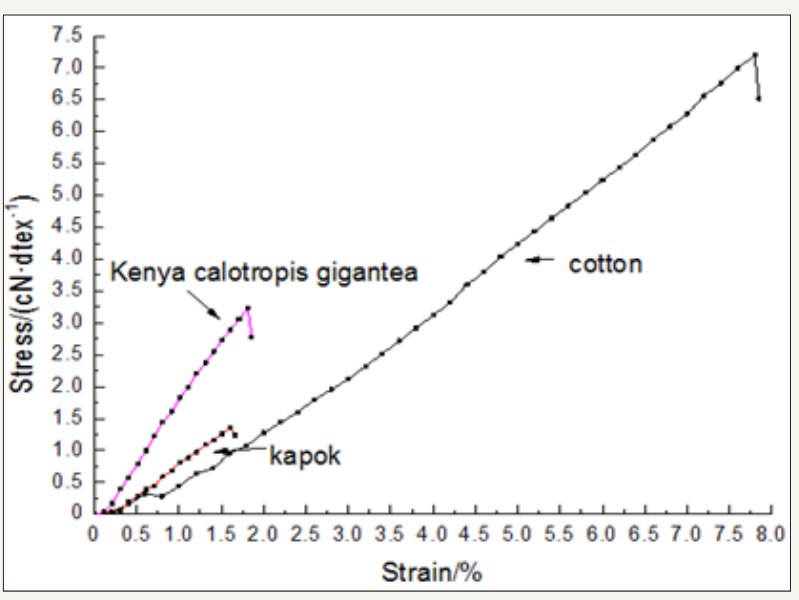

Figure 5: The stress-strain curves of fibers.

Water absorbing capability: The higher crystallinity, the stronger interaction between the molecules in fibers, which mean that water, is not easier to permeate into fibers and thus the fibers have poor hygroscopicity. As illustrated in (Table 4), calotropis gigantea fiber and kapok fiber both have higher moisture regain than cotton fiber. Usually higher crystallinity and COI implying 
lower hygroscopicity because of the lack of amorphous region; however, calotropis gigantea fiber has higher moisture regain than kapok fiber (Table $3 \&$ Table 4). This can be explained by the facts that (1) calotropis gigantea fiber has been distributed with grooves and microvillus along fiber longitudinal axis (Figure 1), thus the fiber has greater specific surface area to absorb water; (2) calotropis gigantea fiber has an open end beneficial to water absorption contrast to the closed end of kapok fiber.

Table 4: The moisture regain of fibers.

\begin{tabular}{|c|c|c|c|}
\hline Fibers & $\begin{array}{c}\text { Calotropis } \\
\text { Gigantea Fiber }\end{array}$ & Kapok Fiber & Cotton Fiber \\
\hline $\begin{array}{c}\text { Moisture } \\
\text { regain/\% }\end{array}$ & 12.65 & 11.24 & 8.25 \\
\hline
\end{tabular}

Sweat releasing capability: The sweat releasing capability is directly related to the rapidity of sweat evaporating from our bodies. A fabric with good quick-drying property includes excellent sweat (water) absorption capability and rapid sweat (water) transmitting capability. The investigation on fiber hygroscopicity shows that calotropis gigantea fiber has good sweat (water) absorption capability as displayed in (Table 5). The sweat transportability of fibers is shown in (Table 5). It can be seen that calotropis gigantea fiber, as well as kapok fiber, has as high as more than $97 \%$ sweat transmissibility, meaning almost total amount of sweat absorbed by the fibers are released to the air, while only about half of the initial amount is released regarding of cotton fiber. A conclusion can be drawn that calotropis gigantea fiber has the best sweat (water) absorption and transmitting capability, indicating it can make fabrics with good comfortability.

Table 5: The sweat transmissibility of fibers.

\begin{tabular}{|c|c|c|c|c|}
\hline Fibers & $\mathbf{m}_{\mathbf{0}} \mathbf{( g )}$ & $\mathbf{m}_{\mathbf{1}} \mathbf{( g )}$ & $\mathbf{m} \mathbf{( g )}$ & $\mathbf{( \% )}$ \\
\hline $\begin{array}{c}\text { Calotropis } \\
\text { gigantea } \\
\text { fiber }\end{array}$ & 1.0053 & 3.0800 & 1.0545 & 97.63 \\
\hline Kapok fiber & 1.0000 & 2.9980 & 1.0488 & 97.56 \\
\hline Cotton fiber & 1.0011 & 3.4600 & 2.1405 & 53.66 \\
\hline
\end{tabular}

\section{Conclusion}

The investigation on calotropis gigantea fiber was conducted in this paper, and some new discoveries were obtained. Experimental results indicate that the fiber is decreasing in diameter from end to tip, which are coarser, open and sharper, closed, respectively. The fiber has high hollowness and 4-6 grooves along its longitudinal axis, with fully distributed microvillus on its surface. The FTIR spectrum shows the fiber mainly contain cellulose, lignin and hemi-cellulose component. X-ray diffraction analysis shows that the fiber has higher crystallinity in comparison with kapok fiber. The fiber has higher breaking strength than kapok fiber and good hygroscopicity and water transmissibility, so it is an ideal material to replace some natural cellulose fiber to some extent, such as kapok and cotton.

\section{References}

1. Deshmukh PT, Fernandes J, Atul A, Toppo E (2009) Wound healing activity of Calotropis gigantea root bark in rats. Journal of Ethnopharmacology 125(1): 178-181.

2. Kumar PS, Suresh E, Kalavathy S (2013) Review on a potential herb Calotropis gigantea (L.).Academic Journal of Pharmaceutics 2(2): 135143.

3. Phoo ZWMM, Razon LF, Knothe G, Ilham Z (2014) Evaluation of Indian milkweed (calotropis gigantea) seed oil as alternative feedstock for biodiesel. Industrial Crops and Products 54(4): 226-232.

4. Chamuah SH, Kumar DB, Jatin K (2013) Distribution and abundance of Calotropis gigantea in Guwahati. India Journal of Environment Research Development 8(1): 169-174.

5. Tuntawiroon N, Samootsakom P, Theeraraj G (1984) The Environmental implications of the use of Calotropis gigantea as a textile fabric. Agriculture Ecosystems \& Environment 11(3): 203-212.

6. Sharma P, Sharma JD (1999) Evaluation of in vitro schizontocidal activity of plant parts of Calotropis procera an ethnobotanical approach. J Ethnopharmacol 68(1-3): 83-95.

7. Jayaramudu J, Guduri BR, Rajulu AV (2010) Characterization of new natural cellulosic fabric Grewia tilifolia. Carbohydrate Polymers 79(4): 847-851.

8. Varshney AC, Bhoi KL (1987) Some Possible industrial properties of calotropis procera (Aak) floss fibre. Biology Waste 22(2): 157-161.

9. Sen S, Sahu NP, Mahato SB (1992) Flavonol glycosides from Calotropis gigantea. Phytochemistry 31(8): 2919-2921.

10. Sharma DK, Tiwari M, Arora M (1997) Microbial transformation and biodegradation of Calotropis procera latex towards obtaining value added chemicals, pharmaceuticals and fuels. Petroleum Science and Technology 15(1-2): 137-169.

11. Razon L (2008) Selection of philippine plant oils as possible feedstocks for biodiesel. Philippine Agricultural Scientist 91(3): 278-286.

12. Varshney AC, Bhoi KL (1988) Cloth from bast fiber of the Calotropisprocera (Aak) plant. Biological Waste 26(3): 229-232.

13. Ashori A, Bahreini Z (2009) Evaluation of Calotropis gigantea as a promising raw material for fiber-reinforced composite. Journal of Composite Materials 43(11): 1297-1304.

14. Dilli BG, Sivaji BK, Nanda KP (2014) Tensile and wear behavior of Calotropis gigentea fruit fiber reinforced polyester composites. Procedia Engineering 97: 531-535.

15. Tarabi N, Mousazadeh H, Jafari A, Taghizadeh-Tameh J (2015) Design, construction and evaluation of a fiber extracting machine from Calotropis (milkweed) stems. Engineering Agriculture Environment Food 8(2): 88-94.

16. Jiang X, Cheng LD, Yu JY, Wang Q Stojanovska E, et al. (2012) Relationship between akund fibers 'carding and sliver quality. Advanced Materials Research (476-478): 2014-2019.

17. Behera BK, Arora M, Sharma DK (2000) Studies on biotransformation of Calotropis procera latex - A renewable source of petroleum, value-added chemicals, and products. Energy Sources 22(9): 781-807.

18. Johar N, Ahmad I, Dufresne A (2012) Extraction, preparation and characterization of cellulose fibres and nanocrystals from rice husk. Industrial Crops and Products 37(1): 93-99.

19. Dong T, Xu G, Wang F (2015a) Adsorption and adhesiveness of kapok fiber to different oils. Journal of Hazardous Materials 296: 101-111.

20. Dong T, Xu G, Wang F (2015b) Oil spill cleanup by structured natural sorbents made from cattail fibers. Industrial Crops and Products 76: 25 33. 
21. Dong T, Xu G, Wang F (2015c) Sorption kinetics and mechanism of various oils into kapok assembly. Marine Pollution Bulletin 91(1): 230237.

22. Sealy C (2014) Kapok offers new concept in microbial fuel cells. Mater Today 17: 422-423.
23. Zhang YP, Lynd LR (2004) Toward an aggregated understanding of enzymatic hydrolysis of cellulose: noncomplexed cellulose system. Biotechnol Bioeng 88(7): 797-824.

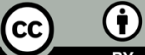

Creative Commons Attribution 4.0 International License

For possible submissions Click Here

\section{Submit Article}

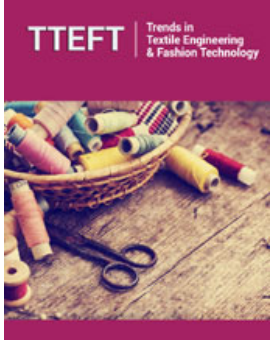

Trends in Textile Engineering \& Fashion Technology

\section{Benefits of Publishing with us}

- High-level peer review and editorial services

- Freely accessible online immediately upon publication

- Authors retain the copyright to their work

- Licensing it under a Creative Commons license

- Visibility through different online platforms 